The effect of vigorous running and cycling on serum COMP, lubricin, and femoral cartilage thickness: a pilot study

Roberts, Harry; Moore, Jonathan; Griffith-Mcgeever, Claire; Fortes, Matthew; Thom, Jeanette

\title{
European Journal of Applied Physiology
}

DOI:

$10.1007 / \mathrm{s} 00421-016-3404-0$

Published: 01/08/2016

Peer reviewed version

Cyswllt i'r cyhoeddiad / Link to publication

Dyfyniad o'r fersiwn a gyhoeddwyd / Citation for published version (APA):

Roberts, H., Moore, J., Griffith-Mcgeever, C., Fortes, M., \& Thom, J. (2016). The effect of vigorous running and cycling on serum COMP, lubricin, and femoral cartilage thickness: a pilot study. European Journal of Applied Physiology, 116(8), 1467-1477.

https://doi.org/10.1007/s00421-016-3404-0

\footnotetext{
Hawliau Cyffredinol / General rights

Copyright and moral rights for the publications made accessible in the public portal are retained by the authors and/or other copyright owners and it is a condition of accessing publications that users recognise and abide by the legal requirements associated with these rights.

- Users may download and print one copy of any publication from the public portal for the purpose of private study or research.

- You may not further distribute the material or use it for any profit-making activity or commercial gain

- You may freely distribute the URL identifying the publication in the public portal?
}

Take down policy

If you believe that this document breaches copyright please contact us providing details, and we will remove access to the work immediately and investigate your claim. 
1 The Effect of Vigorous Running and Cycling on Serum COMP, Lubricin and Femoral Cartilage

2 Thickness: a Pilot Study

3 Harry M. Roberts ${ }^{1}$, Jonathan P. Moore ${ }^{1}$, Claire L. Griffith-McGeever ${ }^{1}$, Matthew B. Fortes ${ }^{1}$ \& Jeanette

4 M. Thom ${ }^{1,2}$

5

$6{ }^{1}$ School of Sport, Health \& Exercise Sciences, Bangor University, UK ${ }^{2}$ School of Medical Sciences,

$7 \quad$ University of New South Wales, Australia

8

9 Corresponding author:

10 Associate Professor Jeanette Thom

11 School of Medical Sciences

12 University of New South Wales Australia

13 Sydney,

$14 \quad$ NSW 2052

15 Australia

16 Phone: +61 (2) 93851090

17 Email: j.thom@unsw.edu.au

Acknowledgments

20 The authors thank all the participants who volunteered for this study. 
Purpose: Our aim was to investigate lubricin, cartilage oligomeric matrix protein (COMP) and femoral cartilage deformation in response to different biomechanical loading of the knee joint (running versus cycling). Methods: Serum lubricin and COMP concentrations enzyme-linked immunosorbent assay (ELISA), and femoral cartilage thickness (supra-patellar transverse ultrasonography) were determined

6 in 11 male runners (age: $40 \pm 6$ years; weight: $76 \pm 8 \mathrm{~kg}$ ) and 11 male cyclists ( $35 \pm 12$ years; $75 \pm 5 \mathrm{~kg}$ ) at baseline, immediately after, and 30 minutes after vigorous exercise (time trial: $10 \mathrm{~km}$ run or $25 \mathrm{~km}$ cycle).

8 Results: At baseline, lubricin (runners: $104.0 \pm 19.8 \mathrm{ng} / \mathrm{ml}$; cyclists: $119.1 \pm 23.9 \mathrm{ng} / \mathrm{ml}$ ) and COMP (runners: $804.1 \pm 87.5 \mathrm{ng} / \mathrm{ml}$; cyclists: $693.0 \pm 84.7 \mathrm{ng} / \mathrm{ml}$ ) did not significantly differ, however, vigorous exercise was accompanied by an increase in lubricin (cyclists: $39.4 \%$; $p<0.05$; runners: $56.9 \%$; $p<0.05$ ) and COMP (cyclists: $32.1 \%$; $\mathrm{p}<0.05$; runners: $14.2 \%$; $\mathrm{p}=0.14$ ) that returned towards baseline following 30 minutes of rest $(\mathrm{p}<0.05)$. No between-group differences were observed for baseline cartilage thickness at the intercondyle notch, medial condyle and lateral condyle, and vigorous exercise did not result in significant change for either group. Conclusions: In the absence of ultrasonographic knee cartilage deformation, the response of serum lubricin and COMP following acute vigorous exercise indicates an increase in joint lubrication and cartilage metabolism, respectively, which appears largely independent of exercise modality.

Key words: knee; joint loading; ultrasound; cartilage oligomeric matrix protein; proteoglygan-4 
1 Abbreviations:

2 COMP Cartilage oligomeric matrix protein

3 ELISA Enzyme-linked immunosorbent assay

4 MRI Magnetic resonance imaging

5 OA $\quad$ Osteoarthritis

6 PRG-4 Proteoglycan-4

7 US Ultrasound

$8 \quad \mathrm{VO}_{2 \max } \quad$ Maximum oxygen uptake

9

10

11

12

13

14

15

16

17

18

19

20

21

22

23 
2 Regular exercise has been shown to preserve knee cartilage volume and thickness (Racunica et al. 2007;

3 Mosher et al. 2010) reduce cartilage defects (Racunica et al. 2007), increase proteoglycan content (Van

4 Ginckel et al. 2010) as well as reduce knee disability and pain (O'Reilly et al. 1999). While regular

5 moderate joint loading may be chondroprotective and promote healthy knee joint function (Urquhart et

6 al. 2011), high levels of joint loading may result in negative adaptations (Driban et al. 2015). Weight

7 bearing activities such as running are associated with much larger lower-body peak forces (D’Lima et

8 al. 2008) and may be subject to an increased risk of osteoarthritis (OA) compared to non-weight bearing

9 activities such as cycling (Vignon et al. 2006; Franciozi et al. 2013). To date, there remains a paucity of

10 research regarding the effect of acute running and cycling exercise on overall joint function.

11 Articular cartilage is an avascular, aneural, and alymphatic tissue which has a crucial role in maintaining

12 mechanical competence through its distribution of large joint loads in a relatively even manner from one

13 subchondral bone plate to another (Mow and Guo 2002). Although mechanical loading is required for

14 tissue maintenance and metabolism, chronic abnormal loading, exaggerated by obesity, joint

15 malalignment or high levels of physical activity, have been implicated as extrinsic risk factors for

16 cartilage damage (Guilak 2011). Articular cartilage is known to deform with exercise (deformational behaviour) before returning to pre-loading values with rest (Kessler et al. 2006). The magnitude of deformation differs between various types of exercise, is 'dose dependent', and may to some extent be related to mechanical differences associated with exercise (Eckstein et al. 2005). Deformational behaviour is also understood to provide unique information regarding the biochemical composition of the cartilage tissue (Eckstein et al. 2006) and has previously been correlated with an exercise-induced increase in cartilage oligomeric matrix protein (COMP) (Kersting et al. 2005).

Clinical measures of early knee joint adaptation are elusive. However, easily accessible serum biomarkers are understood to reflect the release of molecules or molecular fragments from the loaded joint and are increasingly acknowledged as a method to monitor early joint adaptation, degenerative change, and OA (Bauer et al. 2006). COMP is a non-collagenous glycoprotein that binds to type II collagen and functions by assisting with the organisation and stabilisation of articular cartilage (Halász et al. 2007). COMP has previously been used a marker of cartilage metabolism / turnover (Saxne et al. 1992), as well as to monitor cartilage degradation (Neidhart et al. 1997). When cartilage is broken down, 
1 COMP is released into the synovial fluid and later into the blood serum (Sharif et al. 1995). Elevated

2 baseline levels of serum COMP have been established following knee injury (Catterall et al. 2010), OA

3 (Neidhart et al. 2000) and rheumatoid arthritis (Vilím et al. 2003; Law et al. 2015). Thus, it is understood

4 that elevated serum COMP may reflect a shift towards increased cartilage degradation. Elevated baseline

5 levels have also been reported in marathon runners (Neidhart et al. 2000). Previous studies have also

6 demonstrated that exercise results in an acute 'dose dependent' increase in COMP from baseline

7 (Neidhart et al. 2000; Mündermann et al. 2005; Kersting et al. 2005), which has been suggested to relate

8 to increased cartilage turnover to acute tissue loading (Neidhart et al. 2000). Therefore, COMP may be

9 a promising marker to evaluate the effect of acute running and cycling exercise on the knee joint.

10 A second novel and exciting marker is lubricin, a proteoglycan-4 (PRG-4) protein, encoded by the PRG-

114 gene and understood to function by reducing the friction associated with joint movement (Jay et al. 12 2007) and preventing cartilage wear (Rhee et al. 2005). PRG-4 includes the protein lubricin, which is a 13 mucin-like o-linked glycosylated protein, as well as the homologous superficial zone protein, 14 megakaryocyte stimulating factor and hemangiopoietin. These PRG-4 proteins are expressed in skeletal 15 and non-skeletal tissues, with highest levels of expression in articular joints, bone, and liver (Ikegawa et 16 al. 2000; Rhee et al. 2005). Although all PRG-4 proteins are implicated in articular joint protection, 17 current understanding is that lubricin and superficial zone protein have an increased localization to the 18 joint and play the greatest role (Rhee et al. 2005; Jay et al. 2007). In contrast, megakaryocyte stimulating 19 factor and hemangiopoietin are understood to function in the regulation of megakaryopoiesis, and 20 hematopoietic progenitor cell expansion, respectively (Novince et al. 2011); however, there remains less 21 clarity regarding the localization of both megakaryocyte stimulating factor and hemangiopoietin. 22 Importantly, mutations in the PRG-4 gene results in a recessive disorder known as camptodactyly23 arthropathy-coxa vara-pericarditis syndrome, which is a characterized by early-onset joint failure, and 24 thus supports the role of PRG-4 in articular protection. Given our interest in joint function we will refer 25 to the PRG-4 proteins as lubricin, often known synonymously as superficial zone protein or PRG-4. 26 Several in vivo animal studies have provided evidence to suggest that lubricin synthesis is down27 regulated in degenerative joints (Abusara et al. 2013), following anterior cruciate ligament injury (Elsaid 28 et al. 2012) and in a meniscectomy-induced OA model (Young et al. 2006). In contrast, low to moderate 29 mechanical loading has been shown to significantly increase lubricin expression and is associated with 
1 fewer degenerative changes (Ni et al. 2012). Whether exercise in humans has an effect on serum lubricin concentration may be a promising indicator of joint function and to date remains unknown.

In addition to serum biomarkers, ultrasonography (US) of the knee joint is a non-invasive, fast, and inexpensive imaging method that is increasingly used to assess early degenerative change. US is considered an excellent tool to assess several intra-articular abnormalities including knee effusions, synovitis and intra-articular bodies (Abraham et al. 2011; Kazam et al. 2011). US can also be utilised to provide a valid and reliable measure of femoral cartilage thickness at three identifiable locations, the intercondyle notch, medial condyle and lateral condyle (Naredo et al. 2009).

The sonographic evaluation of cartilage thickness, together with biomarkers lubricin and COMP, offer an attractive method to explore the physical and biochemical tissue response following an acute bout of running and cycling. Therefore, the aims of this study were to determine whether: 1) vigorous exercise will increase serum lubricin and serum COMP concentrations, 2) vigorous exercise will decrease cartilage thickness, and 3) trained runners completing a vigorous running protocol respond differently to trained cyclists completing a similarly matched vigorous cycling protocol.

\section{Methods}

\section{Participants}

A homogeneous group of healthy trained runners and cyclists were recruited for this study. In order to maintain a homogeneous sample the inclusion criteria for entry to the study included being male, aged between 18-59 years, and a body mass index of $<30 \mathrm{~kg} / \mathrm{m}^{2}$. Runners were required to have recently completed a $10 \mathrm{~km}$ time trial in under 45 minutes and / or regularly complete > 25 miles per week in training. In comparison, cyclists were required to have recently completed a $25 \mathrm{~km}$ time trial in under 45 minutes and / or regularly complete $>80$ miles per week in training and / or regularly cycle $>4$ hours per week. Cyclists were also required to have a limited history of weight bearing activity and have not completed regular weight bearing sports training or running within the last 6 months. Exclusion criteria for both groups included: (i) diagnosed OA, rheumatoid arthritis, or other inflammatory disease, (ii) history of knee malalignment (varus / valgus) greater than $15^{\circ}$, (iii) previous knee injury (including meniscus tear or ligament damage or tear), (iv) recent fracture of lower extremity (within last 6 months), (v) current or prior use of lipid-lowering therapy (e.g. fibric acids, nicotinic acids, bile acid sequestrates, fish oils), corticosteroid injections, (vi) current or past (within last four weeks) glucosamine and / or 
1 chondroitin supplementation use, (vii) additional exclusion factors included muscle weakness and musculoskeletal / orthopaedic problems prohibiting exercise participation. A control group was not

3 included within this study design due to the difficulties of finding an equally well matched group of trained individuals who did not engage in weight bearing or non-weight bearing activities.

Sample size calculation were conducted prior to commencing testing using G*Power 3.1.3 (HeinrichHeine-University) software. Assuming an alpha value of 0.05 and $80 \%$ power, a total sample size of 24 participants was calculated in order to detect a moderate effect size (0.50). The local University ethics committee approved the study protocol and the study was carried out in compliance with the Helsinki declaration. Written informed consent was obtained from all participants.

\section{Experimental protocol}

All participants were required to visit the physiology laboratories on two separate occasions with a minimum of 48 hours between visits and a maximum of 2 weeks. During the first visit height and body weight were assessed using a calibrated balance beam scale (SECA, California, USA) and wall mounted tape measure (SECA, California, USA), respectively. Subsequently, a venous blood sample (6 ml) was acquired following 15 minutes of seated rest (Mundermann et al 2005), prior to completing an incremental exercise protocol to determine maximum oxygen uptake $\left(\mathrm{VO}_{2 \max }\right)$. During the second visit participants provided an additional venous blood sample $(6 \mathrm{ml})$ and underwent ultrasound scanning of the femoral cartilage (to assess cartilage thickness) of the right leg, before, immediately post, and 30 minutes post the vigorous time trial protocol. Participants were required to limit their training / racing prior to each visit and were unable to take part in the study if they had taken part in a marathon or ultradistance event within 7 days of a testing day. Training within the 48 hours prior to testing was limited to 1 hour of moderate intensity training and participants had to refrain from training in the 24 hours prior to testing. Participants also provided detailed information regarding their typical training (frequency, intensity, duration and type) and provided information regarding their training history (number of years of training).

\section{Serum Lubricin and COMP analysis}

All blood samples were allowed to clot and subsequently centrifuged for 15 minutes $\left(4^{\circ} \mathrm{C}, 1000 \mathrm{~g}\right)$. Serum was immediately frozen to $-80^{\circ} \mathrm{C}$ and stored until analysis. Serum lubricin (PRG-4) was analysed using 

Cusabio Biotech Co, China). Similarly, serum COMP was analysed using a commercially available sandwich ELISA (Human COMP ELISA kit KA0021, Abnova Corporation, Taiwan) as previously described (Law et al. 2015). Intra-assay coefficient of variation was $6.1 \%$ and $6.0 \%$ for lubricin and COMP analysis, respectively, and the $\mathrm{R}^{2}$ curve was $>0.99$ for all curves.

\section{Sonographic Assessment of Cartilage Thickness, Deformation and Recovery}

7 The ultrasound (US) assessment was performed using a $12 \mathrm{MHz}$ linear-array probe (Esaote S.P.A. MyLab50 ultrasound, Firenze, Italy) and acoustic coupling gel (Aquasonic 100, Parker Laboratories, Inc,

9 Fairfield, NJ). With participants lying in a supine position and with the right knee maximally flexed, the superior margin of the patellar was located and a line was marked on the skin using a washable marker at the point immediately above the superior margin of the patellar and at $1 \mathrm{~cm}$ intervals in a superior direction. The transducer was placed in a supra-patella transverse position, perpendicular to the bone surface and orientated to optimise the US image (Naredo et al. 2009; Özçakar et al. 2014). The location at which the cartilage thickness of the intercondyle notch appeared greatest was marked on the skin thus enabling the examiner to return the transducer to the exact location for all subsequent scans; transducer placement was $2.0 \pm 0.5 \mathrm{~cm}$ above the patellar for both right and left knees. The distance from the thin hyperechoic line formed at the synovial space-cartilage border to the line formed at the cartilage-bone border was used to measure minimal cartilage thickness at each location (Özçakar et al. 2014). Cartilage thickness deformation and recovery was calculated as the difference in cartilage thickness between the measure obtained pre-exercise and immediately-post the acute exercise protocol and the measure taken immediately-post and post-30 minutes of seated rest, respectively. The same researcher performed all ultrasonography scans following training by a consultant rheumatologist with expertise using this technique. minimal cartilage thickness at the lateral condyle, medial condyle and intercondylar notch. Anatomic reference points used in the present study corresponded to the midpoint of the intercondyle notch and 1 $\mathrm{cm}$ apart in the medial and lateral direction were used as an estimate of the medial and lateral condyle cartilage thickness (Figure 1); Naredo and colleagues previously demonstrated good reproducibility in femoral cartilage thickness measurement when using comparable anatomical reference points (Naredo 
1 et al. 2009). In addition, our own repeatability study demonstrated a moderate to high intra class

2 correlations for resting femoral cartilage thickness measurements conducted on two separate days (ICC

3 between $0.635-0.807$ for all locations and across age groups; with ICC between $0.800-0.934$ in young

4 individuals and between 0.719 - 0.813 in middle aged individuals). Prior to analysis, all images were de-

5 identified by second researcher for blinded analysis. Based on the pixel resolution (15.8 pixels $/ \mathrm{mm})$ of

6 the images captured by ultrasonography, the ImageJ software allowed images to be measured to an

7 accuracy of greater than one-tenth off a mm, or more specifically, one pixel was equal to $0.06 \mathrm{~mm}$. The

8 cartilage thickness of each image was measured in triplicate and an average of the three measurements

9 was used for all data analysis. As required, the image contrast was adjusted to assist in appropriately

10 identifying the hyperechoic line formed at the synovial space-cartilage border to the line formed at the

11 cartilage-bone border.

\section{Maximum Oxygen Uptake ( $\left.\mathrm{VO}_{2 \max }\right)$}

Breath-by-breath analysis using an online gas analyser (Cortex, Leipzig, Germany) was used to determine cardiorespiratory fitness. Participants in the running group performed an incremental exercise test using the treadmill (HPcosmos Mercury 4 Med, Nussdorf-Traunstein, Germany). In contrast, participants in the cycling group performed an incremental exercise test using the cycle ergometer (Lode Excalibur Sport, Groningen, Netherlands). Heart rate was monitored continuously using a heart rate monitor (Polar Electro, Kempele, Finland) and the rating of perceived exertion was measured using the Borg scale every 3 minutes. $\mathrm{VO}_{2 \max }$ was defined as the highest 30 -s average in $\mathrm{VO}_{2}$ and was accepted if two of the following were met; a plateau in $\mathrm{VO}_{2}$ despite the continuation of exercise, a respiratory exchange ratio $\geq 1.05$, or participants reached $>95 \%$ of predicted maximum heart rate.

\section{Time-trial exercise protocol}

The vigorous exercise protocol was specific to the participant's activity: trained runners completed a 10 $\mathrm{km}$ running time trial using the treadmill ergometer and trained cyclists completed a $25 \mathrm{~km}$ cycling time trial using a cycle ergometer. Runners self-regulated their speed using the treadmill monitor, while the gradient remained standardised at $1 \%$ to account for the lack of wind resistance. Similarly, cyclists also adopted a self-selected workload and cadence. Although participants self-regulated their workload, travelling speed and exercise-time were not provided. Importantly, participants were instructed to complete the time-trial protocol as intensely as possible in order to mimic actual competition. Continuous 
1 verbal encouragement was provided throughout. Both heart rate and rating of perceived exertion

2 measurements were taken at several time points throughout the trial to ensure the protocol replicated

3 competitive conditions.

$4 \quad$ Data analysis

5 Statistical analyses were performed utilising statistical analysis software (SPSS for Windows version

620.0 [SPSS, Chicago, IL, USA]). A two-factor (treatment $x$ time) repeated-measures analysis of variance

7 was used to assess the within groups difference (baseline vs. immediately post-exercise vs 30 minutes

8 post-exercise), between group difference (runners vs. cyclists) and time by treatment interactions (group

9 differences over time) for serum lubricin, serum COMP, and femoral cartilage thickness. A single 10 baseline value (average of visit 1 and visit 2) was used for within group analysis of serum lubricin and 11 COMP in order to determine a robust baseline value and the coefficient of variation was calculated.

12 Significant interactions and / or main effects were analysed post-hoc using Bonferroni-corrected t-tests 13 where appropriate. Independent sample t-tests were used to assess differences between runners and 14 cyclists. Pearson correlations (parametric data) and Spearman's rank correlations (non-parametric data) 15 were performed to examine the relationships between all baseline continuous variables. As appropriate, sensitivity analysis was completed to determine the effect of outliers and to strengthen the conclusions 17 drawn from the analyses. Effect sizes were calculated using the Cohen d equation; 0.2, 0.5 and 0.8 were considered as small, moderate and large effect size, respectively. Normality of data was explored by

19 visual inspection of Q-Q plots and through analysis of the models residuals. All figures and tables are presented as mean \pm standard deviation, with statistical significance set as $(\mathrm{p}<0.05)$.

\section{Results}

Of the twenty-four participants who completed the study, two cyclists revealed a history of weightbearing sporting activity and were consequently removed from study. Therefore, in total, twenty-two participants (running group: $\mathrm{n}=11$; cycling group: $\mathrm{n}=11$ ) were included within the analyses. Both groups were comparable for the number of training years, average number of days and average number of hours of training completed per week (Table 1). Overall, participants within the running and cycling groups can be described as well-trained athletes and provide a good opportunity for comparison between groups. 
1 Following exercise serum lubricin increased significantly irrespective of the exercise modality (Figure

2 2a); concentrations increased by $31.3 \%$ following cycling (baseline: $114.0 \pm 41.8 \mathrm{ng} / \mathrm{ml}$; immediately

3 post-exercise: $166.0 \pm 61.9 \mathrm{ng} / \mathrm{ml}, \mathrm{p}<0.01$ ) and by $35.7 \%$ following running (baseline: $105.0 \pm 29.6$

$4 \mathrm{ng} / \mathrm{ml}$; immediately post-exercise: $163.1 \pm 58.0 \mathrm{ng} / \mathrm{ml}, \mathrm{p}<0.01)$. Thirty minutes of seated rest resulted

5 in a significant decrease towards pre-exercise values in both groups (cycling group: $112.0 \pm 47.1 \mathrm{ng} / \mathrm{ml}$;

6 running group: $122.6 \pm 49.1 \mathrm{ng} / \mathrm{ml}$, both $\mathrm{p}<0.01)$. The impact of exercise on serum lubricin is reinforced

7 by the large effect size observed by the cycling (0.99) and running groups (1.27). There was no significant

8 difference and only a small effect size (0.25) in baseline serum lubricin between cyclists $(114.0 \pm 41.8$

$9 \mathrm{ng} / \mathrm{ml})$ and runners $(105.0 \pm 29.6 \mathrm{ng} / \mathrm{ml})$. Sensitivity analysis did not alter the primary findings and 10 indicated that any difference between baseline lubricin of cyclists and runners may be minimal.

11 Serum COMP

12 Serum COMP concentration increased in both groups following exercise (Figure 2b); however, this 13 increase was significant following cycling only (baseline: $693.9 \pm 189.0 \mathrm{ng} / \mathrm{ml}$; immediately post14 exercise: $916.4 \pm 228.1 \mathrm{ng} / \mathrm{ml}, \mathrm{p}<0.01)$. Although non-significant $(\mathrm{p}=0.14)$, the increase in serum 15 COMP following running (baseline: $804.1 \pm 259.3 \mathrm{ng} / \mathrm{ml}$; immediately post-exercise: $918.1 \pm 290.7$ $\mathrm{ng} / \mathrm{ml}$ ) represented a moderate effect size (0.47). In a similar manner to lubricin, both groups 17 demonstrated a significant return toward pre-exercise values following 30 minutes of seated rest (cycling group: $649.5 \pm 176.2 \mathrm{ng} / \mathrm{ml} ; \mathrm{p}<0.01$, running group $752.6 \pm 244.8 \mathrm{ng} / \mathrm{ml} ; \mathrm{p}<0.05)$. No significant differences at baseline between the cycling and running group were revealed. However, mean baseline COMP tended to be $14 \%$ greater (moderate effect size, 0.48$)$ in runners compared with cyclists $(\mathrm{p}=$ 21 0.27). Sensitivity analysis found serum COMP to be significantly increased following running $(\mathrm{p}<0.05)$ as well as cycling ( $\mathrm{p}<0.01)$; this also indicated that differences in baseline serum COMP between runners and cyclists may actually be minimal.

\section{Sonographic Assessment of Cartilage Thickness, Deformation and Recovery}

Cartilage thickness following running did not significantly change (all p >0.05) at the intercondyle notch (baseline: $2.02 \pm 0.47 \mathrm{~mm}$; immediately post-exercise: $2.14 \pm 0.48 \mathrm{~mm}$ ), medial condyle (baseline: 2.15 $\pm 0.23 \mathrm{~mm}$; immediately post-exercise: $2.09 \pm 0.49 \mathrm{~mm}$ ) or lateral condyle (baseline: $2.05 \pm 0.21 \mathrm{~mm}$; immediately post-exercise: $1.94 \pm 0.34 \mathrm{~mm}$ ). Likewise, there was no significant change (all $\mathrm{p}>0.05$ ) in cartilage thickness following cycling at the intercondyle notch, (baseline: $2.27 \pm 0.38 \mathrm{~mm}$; immediately 
1 post-exercise: $2.38 \pm 0.63 \mathrm{~mm}$ ) medial condyle (baseline: $2.04 \pm 0.32 \mathrm{~mm}$; immediately post-exercise:

$2 \quad 2.02 \pm 0.27 \mathrm{~mm}$ ) or lateral condyle (baseline: $2.15 \pm 0.31 \mathrm{~mm}$; immediately post-exercise: $2.21 \pm 0.28$

$3 \mathrm{~mm}$ ) (Figure 3). In addition, following running and cycling the 30 minutes of seated rest provided did not significantly change intercondyle, medial or lateral femoral cartilage thickness. There was also no significant difference between baseline femoral cartilage thickness of runners and cyclists at the intercondyle notch, medial condyle and lateral condyle cartilage thickness (all p > 0.05). The greatest between group difference in baseline cartilage thickness was observed at the intercondyle notch (running group: $2.02 \pm 0.47 \mathrm{~mm}$ : cycling group $2.27 \pm 0.38 \mathrm{~mm})$ which represented a moderate effect size $(0.58)$.

Correlation analysis

Correlation analysis was performed for the full sample $(n=22)$, with very few correlations observed between outcome measures (Table 2). Advancing age was associated with baseline reduced cartilage thickness at the lateral condyle $(\mathrm{r}=-0.650, \mathrm{p}<0.01)$, while the number of previous training years was associated with increased cartilage thickness at the intercondyle notch $(r=0.481, \mathrm{p}<0.05)$.

\section{Discussion}

To our knowledge this is the first study that has explored the effect of acute exercise on serum lubricin in humans. This study demonstrated that an acute bout of vigorous exercise results in an increase in both serum lubricin and COMP concentrations. In contrast to the serum biomarkers, femoral cartilage thickness was unaffected by vigorous exercise. In relation to the modality of exercise, the increase in serum lubricin following vigorous exercise was comparable for both runners and cyclists. However, unlike serum lubricin, the magnitude of change in serum COMP was less following running compared to cycling. The current study also demonstrates that serum lubricin, serum COMP, and femoral cartilage thickness do not significantly differ at baseline between runners and cyclists. Furthermore, there were no significant correlations between femoral cartilage thickness and either serum biomarker.

The increase in serum lubricin and COMP following acute vigorous cycling and running exercise in healthy humans in the current study are consistent with reports of increased PRG-4 and COMP production in response to mechanical load in cartilage explants and animal models (Piscoya et al. 2005; Nugent-Derfus et al. 2007; Abusara et al. 2013). The increase in serum COMP in the present study is also consistent with several studies that have previously demonstrated that serum COMP increases following exercise (Neidhart et al. 2000; Kersting et al. 2005; Niehoff et al. 2011). The increases in 
serum lubricin and COMP observed in the present study may reflect the release into the synovial fluid and circulation as a result of exercise-induced loading of the knee articular cartilage. However, the release from other joint sources such as the synovium, tendons, ligaments and bone, as well as non-joint sources cannot be discounted.

The elevation in serum lubricin and COMP concentration may be a result of the release of cartilage components into the synovial fluid and circulation in response to exercise. However, the exact mechanisms contributing to the increase in biomarker concentrations and the movement from the extracellular matrix into the bloodstream remains unclear. With regard to serum COMP, elevated levels within the circulation in response to loading may reflect increased cartilage turnover (Saxne et al. 1992), potential tissue damage (Neidhart et al. 2000), or an exercise-induced increase in the transport/removal from the joint into the blood (Helmark et al. 2012). In addition, acute increases in serum biomarkers conceivably may reflect the integrity of the joint. Importantly, joint movement is considered an important factor in increasing intra-articular pressure and possibly contributes to the movement of cartilage constituents into the circulation (Levick and McDonald 1995), thus supporting the exerciseinduced increase observed in the present study.

Given the role of lubricin in reducing the coefficient of friction within the joint (Jay et al. 2007), the acute increase in serum lubricin may reflect a temporary increase in joint lubrication following exercise. This may also explain why exercise has previously been shown to improve symptoms such as knee joint stiffness and pain among individuals with joint disease (O’Reilly et al. 1999). Interestingly, several in vivo animal studies have recently demonstrated that lubricin expression is attenuated under conditions associated with high levels of joint loading, including repeated high intensity exercise and with abnormal loading (Ni et al. 2012; Elsaid et al. 2012; Abusara et al. 2013). Therefore, due to the high impacted loading associated with running loads compared to cyclists we postulated that runners might demonstrate reduced resting lubricin concentrations. However, in contrast to our working hypothesis, no differences were observed between exercise modalities. In addition, there was no correlation between baseline lubricin and any parameter of training history, including miles, frequency or duration of training; however, this could be related to our homogenous sample, which was similar in age, fitness level and training habits. 
1 In terms of serum COMP, increases are typically associated with a 'load-dependent' change, with the greatest increase following extensive running (Neidhart et al. 2000; Niehoff et al. 2011). In the present study serum COMP in the running group increased by $+14.2 \%$ with acute exercise and was comparable to the $+14.7 \%$ increases reported following a 1 hour training run (Kersting et al. 2005 ), and $+15.0 \%$ increase following $31 \mathrm{~km}$ of marathon running in trained endurance runners (Neidhart et al. 2000). However, our finding that serum COMP increased more following cycling versus running $(+32.1 \%$ vs $+14.2 \%$ ) is somewhat surprising given that cycling is associated with lower tibiofemoral forces than running (Kutzner et al. 2012). Besides the magnitude of joint load, loading frequency has been suggested as an important factor in COMP release (Piscoya et al. 2005). However, given that the average cadence of cyclists and the typical stepping rate of recreational runners are similar, it appears unlikely that loading frequency was responsible for the results in the present study. Furthermore, the impact of loading frequency on the acute increase of serum COMP is not a universal finding. Thirty minutes of two different impact-loading conditions, i.e. running (high frequency, low amplitude) and drop landing (low frequency, high amplitude), have also been shown to result in a very similar serum COMP response (Niehoff et al. 2011).

Baseline serum COMP concentrations did not significantly differ between runners and cyclists, and both groups were well within previously reported upper normal limits $(<5000 \mathrm{ng} / \mathrm{ml})$ (Saxne et al. 1992). Previously, baseline concentrations in marathon runners have been shown to be greater than the normal limit of $5000 \mathrm{ng} / \mathrm{ml}$ and comparable to the elevated baseline levels previously reported in individuals following joint injury and in patients with OA (Neidhart et al. 2000; Catterall et al. 2010). The baseline serum COMP concentrations found in our healthy cohort are lower than previously reported in clinical populations, such as OA and rheumatoid arthritis (Neidhart et al. 2000; Law et al. 2015). This difference suggests that the trained runners and cyclists have a healthy cartilage turnover and limited, if any, cartilage degeneration. The greater levels of serum COMP previously reported in marathon runners (Neidhart et al. 2000) may result from differences such as increased training history and / or the onset of early degenerative joint change, or perhaps methodological differences such as the inclusion criteria and exercise restrictions before the blood sampling. The large degree of variation that exists in the reported baseline values indicates caution is warranted when comparing between studies.

To our knowledge the present study is the first to utilize ultrasonography to assess femoral cartilage thickness at baseline and following exercise in a group of healthy well-trained runners and cyclists. In 
contrast to our initial hypothesis, the results of the current study demonstrate that neither vigorous running nor vigorous cycling resulted in significant deformation of the femoral cartilage. In the present study there was no significant deformation in cartilage thickness following either acute running or cycling. In contrast, running for a period of 30 minutes has previously resulted in cartilage thickness decreases at the femur (4\%-8\%) and tibia (0\%-12\%) in both marathon runners and sedentary controls (Mosher et al. 2010). Significant cartilage thickness deformation has also been demonstrated at the medial femoral condyle (-2.6\%) following 30 minute of running in a sample of healthy young adults (Niehoff et al. 2011). The difference between the exercise-induced decrease in cartilage thickness observed in the aforementioned studies and the present study might relate to the use of ultrasound to measure cartilage thickness compared to magnetic resonance imaging (MRI). Although ultrasonography is valid, reliable (Naredo et al. 2009) and reduces the time-delay in measurement following exercise, MRI not only increases the ability to detect small changes following exercise due to a greater measurement precision, but also provides the opportunity to measure individual cartilage plates as well as total cartilage volume compared femoral cartilage thickness alone. Nonetheless, differences in the frequency and amplitude of mechanical loading may also influence cartilage deformation (Niehoff et al. 2011). Furthermore, it is also possible that differences relate to potential adaptations in the biomechanical and/or mechanical properties of articular cartilage in response to chronic mechanical loading (Van Ginckel et al. 2010); this may explain potential differences between trained and less trained individuals.

The assessment of baseline femoral cartilage thickness using ultrasound has been largely limited to patient cohorts, including for example, individuals with OA (Tarhan et al. 2003), Meniscal injury (Akkaya et al. 2013), spinal cord injury (Kara et al. 2013), and pes planus (or flatfoot) (Öztürk et al. 2015). Furthermore, there remains a paucity of studies using ultrasonography to assess formal cartilage thickness in healthy cohorts. Despite this, one recent study using ultrasonography demonstrated that healthy men whom regularly engage in exercise have thicker femoral cartilage than individuals who do not (Özçakar et al. 2014). Interestingly, in the present study, baseline cartilage thickness did not significantly differ between exercise modalities, though a moderate effect size indicated that runners may perhaps have reduced cartilage thickness at the intercondyle notch compared to cyclists. The effect of 3 months (Cotofana et al. 2010) and 6 months (Hinterwimmer et al. 2013) running training on patellar, femoral and tibial cartilage volume and thickness found limited change, thus suggesting that running training is well tolerated. Furthermore, marathon runners have previously been shown to have 
1 significantly greater femoral cartilage thickness compared to sedentary controls (Mosher et al. 2010).

2 Therefore, weight-bearing exercise, such as running, appears to be both well tolerated and potentially

3 positive for cartilage morphology compared to sedentary behaviour. However, the slightly greater

4 cartilage thickness observed in the cycling group suggests that low impact non-weight bearing exercise,

5 such as cycling, could perhaps provide a slightly superior loading stimulus for cartilage thickness at the weight-bearing femoral intercondyle notch. A larger sized study is required to determine whether cycling is more favourable for the knee joint compared with running. Interestingly, the current study also demonstrated a positive correlation between cartilage thickness and the number of training years across both runners and cyclists. This finding seemingly provides further evidence for the benefits of regular training on cartilage morphology and supports the previous work of Özçakar and colleagues (2014).

Despite our encouraging research we must acknowledge that this study does have some limitations. Although joint structures are understood to be a primary source of lubricin and COMP, both are also expressed in several different tissues and neither are produced exclusively within the knee joint. Further work is therefore required to determine whether serum markers, particularly with exercise, reflect a functional or structural change at the knee joint. Research is also warranted in order to understand the movement of these biomarkers from the joint cavity into the circulating blood. Moreover, the ELISA assay used in the present study to represent serum lubricin detects not only the lubricin protein, but also several post-translational modifications of the PRG-4 gene including, superficial zone protein, megakaryocyte stimulating factor and hemangiopoietin. Therefore, we must not discount that exerciseinduced increases may also reflect an increase from other organs as a consequence of metabolic exerciseinduced stressors. Also, as mentioned previously, we must also acknowledge the shortcomings of US compared to MRI. A study utilising greater variation in athletic ability and the type of exercise training, as well as including a control group may also help establish whether or not differences exist between weight bearing and non-weight bearing exercise.

\section{Conclusion}

Our study suggests that an acute bout of either running or cycling stimulates an increase in cartilage metabolism and may also offer joint protection through lubricin provoked joint lubrication. Given the role of lubricin in maintaining joint function, we suggest that the increase in serum lubricin may indicate a potentially therapeutic and protective benefit at the joint level. Finally, serum lubricin, serum COMP, 
1 and femoral cartilage thickness does not significantly differ between healthy trained runners and cyclists;

2 the reported values would seemingly indicate a natural variation in a group of healthy trained individuals.

3 Future studies should progress these encouraging and novel findings by investigating a larger, less

4 homogenous sample, as well as developing a greater mechanistic understanding regarding the effect of

5 exercise on serum biomarkers in humans.

\section{Conflicts of interest}

7 The authors disclose that no funding was received for this work and have no conflicts of interest to

8 declare.

\section{References}

Abraham AM, Goff I, Pearce MS, Francis RM, Fraser B (2011) Reliability and validity of ultrasound imaging of features of knee osteoarthritis in the community. BMC Musculoskeletal disorders $12: 70$.

Abusara Z, Krawetz R, Steele B et al (2013) Muscular loading of joints triggers cellular secretion of PRG4 into the joint fluid. J Biomech 46:1225-30. doi: 10.1016/j.jbiomech.2013.02.027

Akkaya S, Akkaya N, Ozcakar L, et al (2013) Ultrasonographic evaluation of the femoral cartilage thickness after unilateral arthroscopic partial meniscectomy. Knee Surg Sports Traumatol Arthrosc 21:1104-1110. doi: 10.1007/s00167-012-2081-8

Bauer DC, Hunter DJ, Abramson SB et al (2006) Classification of osteoarthritis biomarkers: a proposed approach. Osteoarthritis Cartilage 14:723-7. doi: 10.1016/j.joca.2006.04.001

Catterall JB, Thomas V Flannery CRS, Kraus VB (2010) Changes in serum and synovial fluid biomarkers after acute injury (NCT00332254). Arthritis Res Ther 12:R229. doi: 10.1186/ar3216

Cotofana S, Ring-Dimitriou S, Hudelmaier M et al (2010) Effects of exercise intervention on knee morphology in middle-aged women: a longitudinal analysis using magnetic resonance imaging. Cells Tissues Organs 192:64-72

D'Lima DD, Steklov N, Patil S, Colwell CW (2008) The Mark Coventry award: In vivo knee forces during recreation and exercise after knee arthroplasty. Clin Orthop Relat Res 466:2605-2611. doi: 10.1007/s11999-008-0345-x 
Driban JB, Hootman JM, Sitler MR, et al (2015) Is Participation in Certain Sports Associated With Knee Osteoarthritis? A Systematic Review. J Athl Train. doi: 10.4085/1062-6050-50.2.08

Eckstein F, Ateshian G, Burgkart R et al (2006) Proposal for a nomenclature for magnetic resonance imaging based measures of articular cartilage in osteoarthritis. Osteoarthr Cartil 14:974-983

Eckstein F, Lemberger B, Gratzke C et al (2005) In vivo cartilage deformation after different types of activity and its dependence on physical training status. Ann Rheum Dis 64:291-5. doi: 10.1136/ard.2004.022400

Elsaid K a, Zhang L, Waller K et al (2012) The impact of forced joint exercise on lubricin biosynthesis from articular cartilage following ACL transection and intra-articular lubricin's effect in exercised joints following ACL transection. Osteoarthritis Cartilage 20:940-8. doi: 10.1016/j.joca.2012.04.021

Franciozi CES, Tarini VAF, Reginato RD et al (2013) Gradual strenuous running regimen predisposes to osteoarthritis due to cartilage cell death and altered levels of glycosaminoglycans. Osteoarthritis Cartilage 21:965-72. doi: 10.1016/j.joca.2013.04.007

Guilak F (2011) Biomechanical factors in osteoarthritis. Best Pract Res Clin Rheumatol 25:815-23. doi: 10.1016/j.berh.2011.11.013

Halász K, Kassner A, Mörgelin M, Heinegård D (2007) COMP acts as a catalyst in collagen fibrillogenesis. J Biol Chem 282:31166-73. doi: 10.1074/jbc.M705735200

Hinterwimmer S, Feucht MJ, Steinbrech C et al (2013) The effect of a six-month training program followed by a marathon run on knee joint cartilage volume and thickness in marathon beginners. Knee Surgery, Sport Traumatol Arthrosc 22:1353-9. doi: 10.1007/s00167-013-2686-6

Ikegawa S, Sano M, Koshizuka Y, Nakamura Y (2000) Isolation, characterization and mapping of the mouse and human PRG4 (proteoglycan 4) genes. Cytogenet Cell Genet 90:291-297. doi: 56791

Jay GD, Torres JR, Rhee DK et al (2007) Association between friction and wear in diarthrodial joints lacking lubricin. Arthritis Rheum 56:3662-9. doi: 10.1002/art.22974

Kara M, Tiftik TT, Öken Ö, et al (2013) Ultrasonographic measurement of femoral cartilage thickness in patients with spinal cord injury. J Rehabil Med 45:145-148. doi: 10.2340/16501977-1092 
Kazam JK, Nazarian LN, Miller TT, et al (2011) Sonographic evaluation of femoral trochlear cartilage in patients with knee pain. J Ultrasound Med 30:797-802.

Kersting UG, Stubendorff JJ, Schmidt MC et al (2005) Changes in knee cartilage volume and serum COMP concentration after running exercise. Osteoarthritis Cartilage 13:925-34. doi: 10.1016/j.joca.2005.06.005

Kessler MA, Glaser C, Tittel S et al (2006) Volume changes in the menisci and articular cartilage of runners: an in vivo investigation based on 3-D magnetic resonance imaging. Am J Sports Med 34:832-6. doi: $10.1177 / 0363546505282622$

Kutzner I, Heinlein B, Graichen F et al (2012) Loading of the Knee Joint During Ergometer Cycling: Telemetric In Vivo Data. J Orthop Sport Phys Ther 42:1032-8

Law R-J, Saynor ZL, Gabbitas J et al (2015) The Effects of Aerobic and Resistance Exercise on Markers of Large Joint Health in Stable Rheumatoid Arthritis Patients: A Pilot Study. Musculoskeletal Care. doi: 10.1002/msc.1103

Levick JR, McDonald JN (1995) Fluid movement across synovium in healthy joints: role of synovial fluid macromolecules. Ann Rheum Dis 54:417-423. doi: 10.1136/ard.54.5.417

Mosher TJ, Liu Y, Torok CM (2010) Functional cartilage MRI T2 mapping: evaluating the effect of age and training on knee cartilage response to running. Osteoarthr Cartil 18:358-364. doi: 10.1016/j.joca.2009.11.011

Mow VC, Guo XE (2002) Mechano-electrochemical properties of articular cartilage: their inhomogeneities and anisotropies. Annu Rev Biomed Eng 4:175-209. doi: 10.1146/annurev.bioeng.4.110701.120309

Mündermann A, Dyrby CO, Andriacchi TP, King KB (2005) Serum concentration of cartilage oligomeric matrix protein (COMP) is sensitive to physiological cyclic loading in healthy adults. Osteoarthritis Cartilage 13:34-8. doi: 10.1016/j.joca.2004.09.007

Naredo E, Acebes C, Moller I et al (2009) Ultrasound validity in the measurement of knee cartilage thickness. Ann Rheum Dis 68:1322-1327. doi: 10.1136/ard.2008.090738

Neidhart M, Hauser N, Paulsson M, et al (1997) Small Fragments of Cartilage Oligomeric Matrix 

Protein in Synovial Fluid and Serum as Markers for Cartilage Degeneration. Rheumatology 36:1151-1160. doi: 10.1093/rheumatology/36.11.1151

Neidhart M, Müller-Ladner U, Frey W et al (2000) Increased serum levels of non-collagenous matrix proteins (cartilage oligomeric matrix protein and melanoma inhibitory activity) in marathon runners. Osteoarthritis Cartilage 8:222-9. doi: 10.1053/joca.1999.0293

Ni G-X, Lei L, Zhou Y-Z (2012) Intensity-dependent effect of treadmill running on lubricin metabolism of rat articular cartilage. Arthritis Res Ther 14:R256. doi: 10.1186/ar4101

Niehoff A, Muller M, Bruggemann L et al (2011) Deformational behaviour of knee cartilage and changes in serum cartilage oligomeric matrix protein (COMP) after running and drop landing. Osteoarthritis Cartilage 19:1003-10. doi: 10.1016/j.joca.2011.04.012

Novince CM, Koh AJ, Michalski MN et al (2011) Proteoglycan 4, a novel immunomodulatory factor, regulates parathyroid hormone actions on hematopoietic cells. Am J Pathol 179:2431-42. doi: 10.1016/j.ajpath.2011.07.032

Nugent-Derfus GE, Takara T, O’Neill JK et al (2007) Continuous passive motion applied to whole joints stimulates chondrocyte biosynthesis of PRG4. Osteoarthritis Cartilage 15:566-74. doi: 10.1016/j.joca.2006.10.015

O'Reilly SC, Muir KR, Doherty M (1999) Effectiveness of home exercise on pain and disability from osteoarthritis of the knee : a randomised controlled trial. Ann Rheum Dis 9:15-19

Özçakar L, Tunç H, Öken Ö et al (2014) Femoral cartilage thickness measurements in healthy individuals: learning, practicing and publishing with TURK-MUSCULUS. J Back Musculoskelet Rehabil 27:117-124. doi: 10.3233/BMR-130441

Öztürk GT, Malas FÜ, Yldzgören MT, et al (2015) Ultrasonographic Assessment of the Femoral Cartilage Thickness in Patients with Pes Planus. Am J Phys Med Rehabil 94:568-572. doi: 10.1097/PHM.0000000000000214

Piscoya JL, Fermor B, Kraus VB et al (2005) The influence of mechanical compression on the induction of osteoarthritis-related biomarkers in articular cartilage explants. Osteoarthr Cartil 13:1092-1099. doi: 10.1016/j.joca.2005.07.003 
Racunica TL, Teichtahl AJ, Wang Y et al (2007) Effect of physical activity on articular knee joint structures in community-based adults. Arthritis Rheum 57:1261-8. doi: 10.1002/art.22990

Rhee DK, Marcelino J, Baker M et al (2005) The secreted glycoprotein lubricin protects cartilage surfaces and inhibits synovial cell overgrowth. J Clin Invest 115:622-31. doi: 10.1172/JCI200522263.622

Roos H, Adalberth T, Dahlberg L, Lohmander LS (1995) Osteoarthritis of the knee after injury to the anterior cruciate ligament or meniscus: the influence of time and age. Osteoarthritis Cartilage 3:261-267. doi: 10.1016/S1063-4584(05)80017-2

Saxne T, Heinegard D, Heinegård D (1992) Cartilage oligomeric matrix protein: a novel marker of cartilage turnover detectable in synovial fluid and blood. Br J Rheumatol 31:583-91.

Sharif M, Saxne T, Shepstone L et al (1995) Relationship between serum cartilage oligomeric matrix protein levels and disease progression in osteoarthritis of the knee joint. Br J Rheumatol 34:30610

Tarhan S, Unlu Z, Goktan C (2003) Magnetic resonance imaging and ultrasonographic evaluation of the patients with knee osteoarthritis: a comparative study. Clin Rheumatol 22:181-8. doi:

\subsection{7/s10067-002-0694-x}

Urquhart DM, Tobing JFL, Hanna FS et al (2011) What is the effect of physical activity on the knee joint? A systematic review. Med Sci Sports Exerc 43:432-42. doi:

$$
\text { 10.1249/MSS.0b013e3181ef5bf8 }
$$

Van Ginckel A, Baelde N, Almqvist KF et al (2010) Functional adaptation of knee cartilage in asymptomatic female novice runners compared to sedentary controls. A longitudinal analysis using delayed Gadolinium Enhanced Magnetic Resonance Imaging of Cartilage (dGEMRIC). Osteoarthr Cartil 18:1564-1569. doi: 10.1016/j.joca.2010.10.007

Vignon É, Valat JP, Rossignol M et al (2006) Osteoarthritis of the knee and hip and activity: a systematic international review and synthesis (OASIS). Jt Bone Spine 73:442-455. doi: 10.1016/j.jbspin.2006.03.001

Vilím V, Vobůrka Z, Vytášek R, et al (2003) Monoclonal antibodies to human cartilage oligomeric 

328:59-69. doi: 10.1016/S0009-8981(02)00375-3

3 Young AA, McLennan S, Smith MM et al (2006) Proteoglycan 4 downregulation in a sheep

4 meniscectomy model of early osteoarthritis. Arthritis Res Ther 8:R41. doi: 10.1186/ar1898 
Table 1. Participant training habits and time trial performance

\begin{tabular}{|c|c|c|c|c|}
\hline \multirow{2}{*}{ Variable } & \multicolumn{2}{|c|}{ 10-km Run $(n=11)$} & \multicolumn{2}{|c|}{ 25-km Cycle $(n=11)$} \\
\hline & Mean \pm SD & Range & Mean \pm SD & Range \\
\hline $\mathrm{VO}_{2 \max }\left(\mathrm{L} \cdot \mathrm{min}^{-1}\right)$ & $4.3 \pm 0.3$ & $(3.6-5.0)$ & $4.4 \pm 0.6$ & $(3.1-5.0)$ \\
\hline Training experience (years) & $7.7 \pm 6.5$ & $(1-22)$ & $5.0 \pm 4.9$ & $(1-15)$ \\
\hline Weekly distance (miles) & $36.8 \pm 11.1$ & $(25-60)$ & $114.5 \pm 41.8 * *$ & $(60-170)$ \\
\hline Weekly frequency (days) & $4.9 \pm 1.4$ & $(3-7)$ & $4.0 \pm 1.4$ & $(2-6)$ \\
\hline Training duration (hours) & $7.1 \pm 2.4$ & $(4.0-10.5)$ & $7.7 \pm 2.1$ & $(5.5-12)$ \\
\hline TT times (min:sec) & $46: 15 \pm 5: 38$ & $(39: 53-49: 02)$ & $37: 39 \pm 2: 30 * *$ & $(34: 03-42: 16)$ \\
\hline
\end{tabular}

Significant difference between groups $(* p<0.05 ; * * p<0.01)$. Values are the mean \pm SD unless otherwise stated 
Table 2. Correlations between physical / exercise / training related parameters and parameters of joint function

\begin{tabular}{|c|c|c|c|c|c|c|c|}
\hline \multirow{2}{*}{ Parameter } & \multirow{2}{*}{$\begin{array}{l}\text { COMP } \\
\text { baseline }\end{array}$} & \multicolumn{3}{|c|}{ Lubricin } & \multicolumn{3}{|c|}{ Baseline cartilage thickness } \\
\hline & & COMP & baseline & Lubricin & Notch & Medial & Lateral \\
\hline Age & 0.177 & -0.130 & 0.010 & 0.271 & -0.249 & -0.064 & $-0.650 * *$ \\
\hline Body mass & 0.325 & -0.292 & 0.079 & -0.064 & 0.272 & 0.012 & 0.114 \\
\hline BMI & 0.268 & 0.134 & -0.022 & 0.150 & 0.286 & -0.066 & -0.124 \\
\hline Body fat \% & 0.163 & 0.193 & 0.049 & 0.136 & 0.039 & -0.205 & -0.259 \\
\hline $\mathrm{VO}_{2 \max }$ & -0.198 & -0.140 & -0.169 & -0.202 & 0.158 & 0.326 & 0.298 \\
\hline TT-time & 0.104 & -0.141 & -0.176 & 0.062 & -0.236 & 0.112 & -0.255 \\
\hline Training years & 0.316 & -0.207 & 0.021 & 0.350 & $0.481 *$ & 0.323 & 0.093 \\
\hline Training miles & -0.008 & 0.160 & 0.011 & 0.128 & 0.242 & -0.230 & 0.225 \\
\hline Training frq / wk & 0.138 & -0.182 & -0.151 & -0.386 & -0.165 & 0.037 & 0.088 \\
\hline
\end{tabular}

$\Delta$, change from baseline to immediately post exercise; $(* p<0.05 ; * * p<0.01)$ 


\section{Figure captions:}

Fig. 1 Images to show ultrasound assessment methodology. a) Demonstrating supra patellar transverse placement of the US probe and b) anatomical marking to ensure correct placement and re-placement of US probe. c) US transverse image of the femoral articular cartilage; $\mathrm{M}$, represents location of medial condyle; N, intercondyle notch; L, lateral condyle

Fig. 2 Mean a) serum lubricin and b) COMP concentrations, pre-exercise, immediately post, and 30 minutes post a $10 \mathrm{~km}$ running or a $25 \mathrm{~km}$ cycling time trial. $*$ and $* *=$ significant difference over time at $p<0.05$ level and $p<0.01$ level, respectively. Significance marked above data line represents cycling group and below represents running group. Data are means \pm standard deviation

Fig. 3 Mean cartilage thickness $(\mathrm{mm})$ pre-exercise, immediately post, and 30 minutes post a $10 \mathrm{~km}$ running or a $25 \mathrm{~km}$ cycling time trial for a) intercondyle notch, b) medial condyle, and c) lateral condyle. Data are means \pm standard deviation 